\title{
Aerosolized Antibiotics for Treatment of Pneumonia in Mechanically Ventilated Subjects
}

\author{
Fatima J Wong, Tina Dudney, and Rajiv Dhand
}

\author{
Introduction \\ Ventilator-Associated Infections \\ Epidemiology \\ Pathophysiology \\ Airway Colonization, Ventilator-Associated Tracheobronchitis, and \\ VAP \\ Aerosolized Agents \\ Aerosolized Antibiotics \\ Advantages of Aerosolized Antibiotics \\ Optimizing Delivery of Aerosolized Antibiotics \\ Pharmacokinetics \\ Clinical Application of Aerosolized Antibiotics for Treatment of VAP \\ For Prevention \\ As Monotherapy \\ As Adjunct Therapy With Systemic Antibiotics \\ For Treatment of Extensively Drug-Resistant or Pan Drug-Resistant \\ Infections \\ Limitations and Barriers to Use of Aerosolized Antibiotics \\ The Future for Aerosolized Antibiotics \\ Conclusions
}

Mechanical ventilation is a well-established and commonly employed modality of treatment for critically ill patients in the ICU. Pneumonia is a frequent complication in mechanically ventilated patients. Patients who develop ventilator-associated pneumonia (VAP) incur higher medical costs, have prolonged ICU and hospital stays, and have increased mortality risk. There is growing interest in finding new treatment modalities for this condition because the success rate for treating VAP with systemic antibiotics continues to be $<70 \%$. Accordingly, clinicians are reevaluating the role of aerosolized antibiotics, either as a sole therapy or as adjuncts to systemic antibiotics, in an attempt to improve clinical outcomes in patients with VAP. There are several clinical settings in which aerosolized antibiotics could be used for treating pneumonia, including their use for prevention, as monotherapy, as adjunctive therapy with systemic antibiotics, and for treatment of extensively drug-resistant or pan drug-resistant pathogens. However, aerosolized antibiotics have not been uniformly effective for improving clinical outcomes of patients with VAP, and local and systemic side effects could complicate their use. Moreover, many questions about aerosolized antibiotics, such as optimal formulations and dosage and treatment regimens, remain unanswered and warrant future investigations. Key words: Multidrug-resistant infections; artificial respiration; ventilator-associated pneumonia; ICU infection; inhalation therapy; nebulizers. [Respir Care 2019;64(8):962-979. () 2019 Daedalus Enterprises] 


\section{Aerosolized Antibiotics in Mechanically Ventilated Subjects}

\section{Introduction}

Ventilator-associated pneumonia (VAP) is a common, hospital-acquired infection that affects $10-40 \%$ of mechanically ventilated patients in the ICU. ${ }^{1}$ VAP is typically defined as pneumonia occurring at least $48-72 \mathrm{~h}$ after endotracheal intubation, although there is no accepted standard definition. Typical clinical features of VAP include detection of a new pulmonary infiltrate on chest radiography along with clinical evidence suggesting an infectious origin, such as onset of fevers, purulent sputum, abnormal white cell count, and deteriorating oxygenation status in a patient receiving mechanical ventilation (Table 1). ${ }^{2-5}$ The development of VAP is associated with several adverse consequences, including longer duration of mechanical ventilation, prolonged ICU length of stay, and increased health care costs. ${ }^{6,7}$ Gram-negative bacilli, such as Pseudomonas aeruginosa, are common pathogens causing VAP. Other causative pathogens include Enterobacteriaceae, Klebsiella pneumoniae, Haemophilus influenzae, Escherichia coli, and Streptococcus pneumoniae. Unfortunately, there has been an increasing trend in recent years in the occurrence of multidrug-resistant (MDR) pathogens such as $P$. aeruginosa and Acinetobacter species as causative organisms for VAP. ${ }^{7-9}$

After establishing the diagnosis of VAP, the next essential step is to initiate appropriate antimicrobial therapy because any delay in treatment increases the patient's mortality risk. ${ }^{2,8}$ To avoid adverse outcomes, antibiotics are given empirically in such patients before culture results are available. This is a common clinical practice, and a diagnosis of VAP accounts for $\sim 50 \%$ of all antibiotics prescribed in the ICU. ${ }^{10}$ The current standard of care is to initiate empiric antibiotic treatment depending on the duration of mechanical ventilation, the local antibiogram pro-

The authors are affiliated with the Division of Pulmonary and Critical Care Medicine, Department of Medicine, Graduate School of Medicine, University of Tennessee Health Sciences Center Knoxville, Knoxville, Tennessee.

Dr Dhand has disclosed relationships with Bayer, GSK, BI, Astra Zeneca, Sunovion, and Cipla. Ms Wong and Dr Dudney have disclosed no conflicts of interest.

Dr Dhand presented a version of this paper at the New Horizons Symposium: Ventilator-Associated Events - Surveillance and Understanding of the AARC Congress 2018, held December 4-7, 2018 in Las Vegas, Nevada.

Correspondence: Rajiv Dhand MD FAARC, Division of Pulmonary and Critical Care Medicine, Department of Medicine, Graduate School of Medicine, University of Tennessee Health Sciences Center Knoxville, 1924 Alcoa Highway, U114, Knoxville, TN 37920. E-mail: rhand@utmck.edu.

DOI: $10.4187 /$ respcare. 07024 file and the patient's risk factors for infection with MDR pathogens. . 7,8 Due to the increasing trend of MDR or extensively drug-resistant Gram-negative bacteria, physicians have used aerosolized antibiotics in conjunction with systemic antibiotic regimens to treat these serious infections in many ICUs throughout the world. ${ }^{10}$

The use of aerosolized antibiotics currently is not widely accepted; however, several investigations, including observational studies and randomized, controlled trials along with systematic reviews and meta-analyses, have evaluated the efficacy of incorporating aerosolized antibiotics in regimens for treatment of VAP. ${ }^{11-35}$ This review will focus on recent developments and the limitations and challenges involved in using aerosolized antibiotics for treatment of VAP.

\section{Ventilator-Associated Infections}

\section{Epidemiology}

Respiratory infections occur frequently among mechanically ventilated patients. A 1-d point prevalence survey in 75 countries involving 13,796 adult patients in 1,265 ICUs reported a respiratory tract infection in $\sim 32 \%$ of patients, and $67.5 \%$ of infected patients were receiving mechanical ventilation. ${ }^{1,36}$ After $\geq 2 \mathrm{~d}$ of mechanical ventilation, $\sim 10 \%$ of patients develop VAP with an attributable mortality of $13 \%$ and associated costs of $\$ 40,000$ for each patient. ${ }^{6,37}$ From 2006 to 2012, there was a decline in the incidence of VAP reported to the Centers for Disease Control and Prevention (CDC) National Healthcare Safety Network. Likewise, medical and surgical ICUs reported a decline in the incidence rate of VAP by $71 \%$ and $62 \%$, respectively, over a 6-y period. ${ }^{1,38}$ An analysis of Medicare Patient Safety Monitoring System data between 2005 and 2013 that was limited to Medicare recipients age $\geq 65$ y found no change in VAP rates, with an observed annual rate ranging between $9.7 \%$ and $10.8 \%$ of patients receiving mechanical ventilation for $\geq 2 \mathrm{~d} .{ }^{38}$

\section{Pathophysiology}

The mere placement of an endotracheal tube increases the risk of developing pneumonia by $6-20$ times compared to this risk in nonintubated individuals. ${ }^{39}$ Three potential conditions or infectious complications are described in patients receiving mechanical ventilation: airway colonization, ventilator-associated tracheobronchitis, and VAP. ${ }^{3}$ These 3 conditions are believed to represent a continuum, with development of VAP being the most serious complication that is associated with increased morbidity and mortality.

The development of airway colonization, ventilator-associated tracheobronchitis, and VAP requires an intricate and complicated series of events involving an artificial 


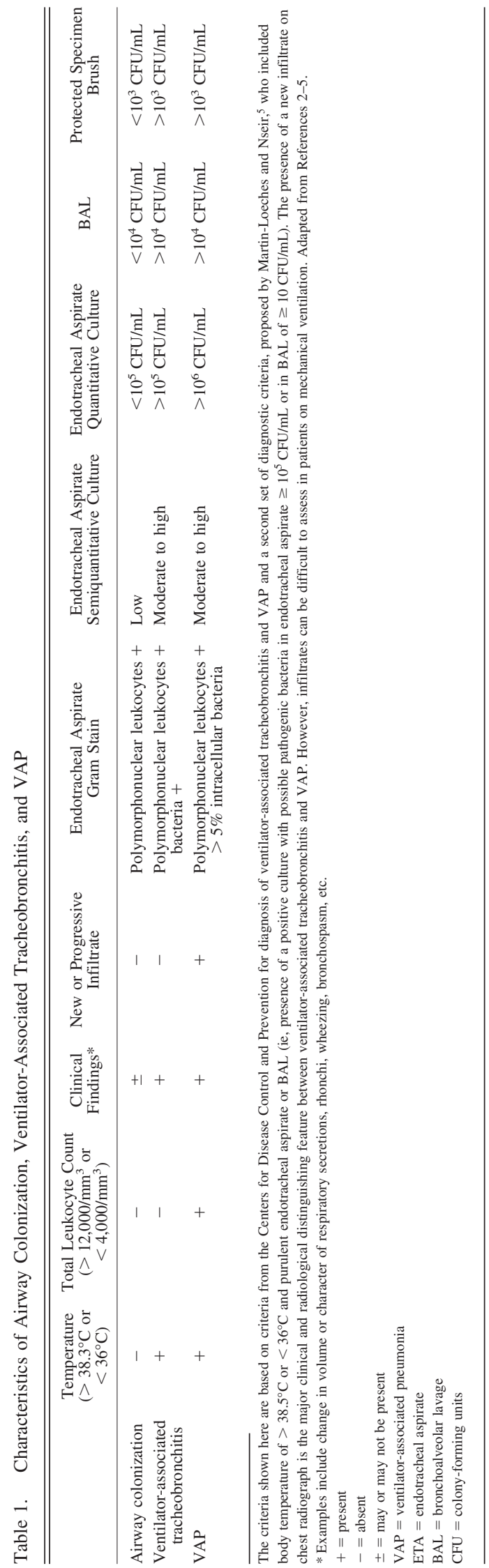

airway (eg, an endotracheal tube), various risk factors, virulence of the invading pathogen, and the host's immune status. ${ }^{2,4}$ Placement of an endotracheal tube leads to an impairment of the patient's natural defenses, such as suppression of the cough reflex, which could prevent microaspiration around the endotracheal tube cuff. Kalanuria and co-workers ${ }^{2}$ described various mechanisms along with microaspiration that enable the introduction of bacteria into the respiratory tract, such as the presence of biofilm within the endotracheal tube, accumulation of secretions around the inflated cuff, and disturbances in mucociliary clearance. In addition, the positive pressure from the ventilator propels bacteria within the lumen of the endotracheal tube further into the respiratory tract. ${ }^{2}$

The risk for development of VAP increases with the duration of mechanical ventilation. However, several independent high-risk factors predispose a patient to developing VAP: male sex, admission following trauma, and an intermediate severity of their underlying condition as assessed by their predicted mortality at the time of admission. ${ }^{2,40}$

\section{Airway Colonization, Ventilator-Associated Tracheobronchitis, and VAP}

Any individual on mechanical ventilation is at risk for developing conditions identified as ventilator-associated lower respiratory tract infections. ${ }^{4,5}$ The presence of microorganisms in the respiratory tract does not always lead to an overt clinical infectious picture in the absence of clinical or radiological findings. This condition has been often described as airway colonization, with microbiological samples yielding $<10^{5}$ colony-forming units $/ \mathrm{mL}$.,5,41 $^{4}$ The view that is currently accepted by many investigators in the field is that ventilator-associated tracheobronchitis is an intermediate entity between airway colonization and VAP. ${ }^{41}$ The estimated incidence of ventilator-associated tracheobronchitis in ICU patients is $2.7-16.5 \%$, with the potential evolution into VAP caused by the same bacterial pathogens. There are similar clinical and microbiological characteristics between ventilator-associated tracheobronchitis and VAP, including the presence of hypo- or hyperthermia, abnormal white blood cell counts, and change in respiratory secretions. However, the one feature that distinguishes between these 2 conditions is the presence of a new or progressive pulmonary infiltrate on chest radiography in patients with VAP (Table 1). ${ }^{3-5,41}$

The accepted standard for diagnosing VAP is through histopathology; however, the lack of standardized objective clinical criteria compromises the specificity to diagnose this condition. The pneumonia definitions, initially formulated by the CDC in the late 1990s, were implemented in the early 2000s and included 3 different sets of criteria along with a conglomerate of radiographic, clini- 
cal, and laboratory data. However, these definitions were time consuming and lacked sensitivity and specificity. Beginning in 2009 and implemented in 2011, the CDC established a new algorithm in an effort to revise the pneumonia definitions. The new algorithm, termed as ventilator-associated events, could then evolve into an infection-related ventilator-associated complication, either as possible or probable VAP. ${ }^{42}$ The first step in the new algorithm places emphasis on a patient's decline after at least $2 \mathrm{~d}$ of clinical stability. A ventilator-associated event or condition is diagnosed when a patient develops either an increased need for $\mathrm{F}_{\mathrm{IO}_{2}}$ or PEEP.

The American College of Chest Physicians (ACCP) proposed alternative criteria for diagnosing VAP, which included a new or progressive infiltrate on chest radiographic imaging in addition to 2 or more of the following markers: fever, abnormal white blood cell count, and purulent secretions. Skrupky and colleagues ${ }^{43}$ compared the CDC criteria and the ACCP criteria to survey for VAP, and they reported that more cases were diagnosed with VAP by applying the ACCP criteria than with the $\mathrm{CDC}$ criteria. By the CDC criteria, only 12 cases $(0.6 \%)$ were diagnosed with pneumonia, whereas $83(4 \%)$ cases were diagnosed with the ACCP criteria. ${ }^{43}$ Moreover, in the 83 subjects diagnosed with the ACCP criteria, 11 (13.3\%) had microorganisms isolated that were resistant to the initially prescribed antibiotic regimen. ${ }^{43}$

Initiation of appropriate antibiotics at the earliest opportunity is the primary mainstay of treatment of VAP. Initially, empiric antibiotics are given depending on a patient's risk for MDR pathogens. Failure to start appropriate treatment has dire consequences, including longer ICU or hospital length of stay, increasing hospital costs, and mortality.7,8,37 The standard of care for treatment of VAP is to administer systemic antibiotics parenterally. The choice of antibiotics has been historically dependent on several factors, such as the duration of mechanical ventilation, the patient's risk factors for MDR pathogens based on prior intravenous (IV) antibiotic use within $90 \mathrm{~d}$, septic shock at time of VAP, ARDS, $\geq 5 \mathrm{~d}$ of hospitalization prior to the occurrence of VAP, or acute renal replacement therapy prior to VAP onset. ${ }^{7}$ Two categories of VAP have been described: early-onset VAP (ie, $<4 \mathrm{~d}$ from intubation) versus late-onset VAP $(>4 \mathrm{~d})$. Early-onset VAP could be empirically treated with limited-spectrum antibiotics, such as $\beta$-lactams, flouroquinolones, or ertapenem, which are similar to those used for treatment of severe communityacquired pneumonia, if the patient does not possess risk factors for MDR pathogens. ${ }^{4}$ In contrast, treatment is empirically begun with broad-spectrum antibiotics for late-onset VAP because of the increased risk for MDR pathogens such as $P$. aeruginosa, Acinetobacter baumannii, and methicillinresistant Staphylococcus aureus. 4,, 37 Despite treatment with systemic antibiotics, there are data indicating that there are still treatment failures with treating VAP. A meta-analysis of trials looking at VAP treatment reported that $37 \%$ of patients failed therapy with IV antibiotics alone. ${ }^{44}$ Even with treatment, VAP is associated with a significant mortality risk. A meta-analysis estimated the attributable mortality due to VAP at $13 \%$, with the risk for mortality being higher in surgical subjects and those subjects whose severity scores were in the mid-range of their underlying conditions. ${ }^{8}$

\section{Aerosolized Agents}

Several medications are administered by aerosolization to mechanically ventilated patients. For example, bronchodilators (eg, $\beta$-agonists and anticholinergics) are the most common medications that are administered as a nebulized form or via pressurized metered-dose inhalers. ${ }^{45}$ Several other medications, such as prostaglandins, mucolytics, antibiotics, antiviral, antifungal medications, corticosteroids, and surfactant ${ }^{45,46}$ have also been administered as aerosols to patients receiving mechanical ventilation.

\section{Aerosolized Antibiotics}

Experience with using inhaled antibiotics has varied. Aerosolized antibiotics have been employed in a wide range of clinical settings, such as infections including ventilatorassociated tracheobronchitis and VAP, and in populations of patients with cystic fibrosis, tuberculosis, non-cystic fibrosis bronchiectasis, or COPD (Table 2). ${ }^{10,11,46-50}$

\section{Advantages of Aerosolized Antibiotics}

Adequate antibiotic concentrations at the source of infection are required to ensure effective therapy. IV antibiotics usually exhibit poor lung tissue penetration and thus require higher doses; higher doses could be associated with systemic adverse effects, including renal or neurological toxicity, bacterial resistance, and treatment failure. Aerosolized antibiotics have several advantages over parenterally administered antibiotics in the treatment of ICUrelated pneumonia. Specifically targeting the lung achieves high alveolar antibiotic concentrations while minimizing systemic exposure (see below).

A noteworthy advantage of inhaled antibiotic therapy is the ability to treat pulmonary infections caused by MDR organisms. Because these medications are administered through the endotracheal tube, the antibiotic comes in direct contact with the tubing system, thereby leading to penetration of the biofilm and limiting quorum sensing. 3,10,48,51 Increased lung concentrations with aerosolized antibiotics can greatly exceed the minimum inhibitory concentration of infecting pathogen(s), therefore enabling the eradication of strains that are categorized as being resistant to conventional parenterally administered antibiotics. This 
Table 2. Aerosolized Antimicrobials and Their Clinical Uses*

\begin{tabular}{|c|c|c|c|c|}
\hline Antimicrobial & Clinical Uses & Formulation & Administration & Adverse Effects \\
\hline \multicolumn{5}{|l|}{ Aminoglycosides } \\
\hline Gentamicin & $\mathrm{CF}, \mathrm{NCFB}, \mathrm{VAP}$ & Inhalation & Nebulizer & Bronchospasm \\
\hline Amikacin & CF, NCFB, VAP, NTMB & $\begin{array}{l}\text { Liposomal formulation } \\
\text { Nonliposomal formulation } \\
\text { Inhalation }\end{array}$ & Nebulizer & $\begin{array}{l}\text { Hearing loss, nephrotoxicity, vertigo, } \\
\text { dysphonia }\end{array}$ \\
\hline Tobramycin & $\begin{array}{l}\mathrm{CF}, \mathrm{NCFB}, \mathrm{VAP}, \mathrm{COPD} \text {, post-lung } \\
\text { transplant infections }\end{array}$ & & $\begin{array}{l}\text { Nebulization } \\
\text { Dry powder } \\
\text { inhaler }\end{array}$ & $\begin{array}{l}\text { Bronchospasm, hearing loss, tinnitus, } \\
\text { voice alteration }\end{array}$ \\
\hline \multicolumn{5}{|l|}{ Polymyxins } \\
\hline Colistin & $\begin{array}{l}\text { CF, NCFB, VAP, post-lung } \\
\text { transplant infections }\end{array}$ & Inhalation & $\begin{array}{l}\text { Nebulizer } \\
\text { Dry powder } \\
\quad \text { inhaler }\end{array}$ & Bronchospasm, throat irritation \\
\hline $\begin{array}{l}\text { Colistimethate } \\
\text { sodium }\end{array}$ & CF, NCFB, VAP & Inhalation & $\begin{array}{l}\text { Nebulizer } \\
\text { Dry powder } \\
\text { inhaler }\end{array}$ & Cough, bronchospasm \\
\hline \multicolumn{5}{|l|}{ Glycopeptides } \\
\hline Vancomycin ${ }^{11}$ & Nosocomial pneumonia & $100 \mathrm{mg} 4$ times daily & Jet nebulizer & $\begin{array}{l}\text { Myocardial infarction, Gram- } \\
\text { negative septic shock, } \dagger \\
\text { nephrotoxicity, bronchospasm }\end{array}$ \\
\hline \multicolumn{5}{|l|}{ Monobactams } \\
\hline $\begin{array}{l}\text { Aztreonam } \\
\beta \text {-lactams }\end{array}$ & $\mathrm{CF}$ & Inhalation & Nebulizer & Wheezing, bronchospasm \\
\hline Ceftazidime & CF, VAP & Inhalation & Nebulizer & Wheezing, cough \\
\hline \multicolumn{5}{|l|}{ Fluoroquinolones } \\
\hline Ciprofloxacin & $\mathrm{CF}$ & $\begin{array}{l}\text { Liposomal solution for inhalation } \\
\text { Dry powder }\end{array}$ & $\begin{array}{l}\text { Nebulizer } \\
\text { Dry powder } \\
\text { inhaler }\end{array}$ & Bronchospasm \\
\hline $\begin{array}{l}\text { Levofloxacin } \\
\text { Antifungals }\end{array}$ & CF, NCFB, VAP & Inhalation & Nebulizer & None reported \\
\hline Amphotericin & $\begin{array}{l}\text { Pulmonary aspergillosis in AIDS, } \\
\text { post-lung transplant }\end{array}$ & $\begin{array}{l}\text { Deoxycholate } \\
\text { Liposomal formulation }\end{array}$ & Nebulizer & $\begin{array}{l}\text { Bronchospasm, shortness of breath, } \\
\text { cough, taste disturbances, chest } \\
\text { tightness, nausea, vomiting }\end{array}$ \\
\hline Pentamidine & PJP prophylaxis & $300 \mathrm{mg}$ every $4 \mathrm{wk}$ & Nebulizer & $\begin{array}{l}\text { Cough, throat irritation, } \\
\text { bronchospasm, fatigue, dizziness }\end{array}$ \\
\hline \multicolumn{5}{|c|}{$\begin{array}{l}\text { * Commercially available and investigational agents are listed. } \\
\dagger \text { Side effects described for a regimen consisting of a combination of IV linezolid, rifampin, intratracheal vancomycin, nasal mupirocin, and cutaneous and oropharyngeal chlorhexidine plus povidone } \\
\text { iodine. } \\
\text { CF }=\text { cystic fibrosis } \\
\text { NCFB = non-cystic fibrosis bronchiectasis } \\
\text { VAP }=\text { ventilator-associated pneumonia } \\
\text { NTMB = nontuberculous mycobacteria } \\
\text { AIDS = acquired immune deficiency syndrome } \\
\text { PJP = Pneumocystis jirovecii pneumonia }\end{array}$} \\
\hline
\end{tabular}

reduces the selection pressure for MDR organisms. In addition, there is a potential to reduce the overall use and duration of systemic antibiotic therapy.52,53

\section{Optimizing Delivery of Aerosolized Antibiotics}

Ensuring efficient delivery of nebulized antibiotics to mechanically ventilated patients requires consideration of several factors and characteristics involving the nebulizer, ventilator, and medication. For example, the type of nebulizer utilized may greatly influence the efficiency and concentration of antibiotics delivered to the lungs. Jet, ultrasonic, and vibrating mesh nebulizers are the currently available types of aerosol generators used to aerosolize antibiotics in ICUs around the world. Each nebulizer has its own advantages, disadvantages, and unique characteristics (Table 3). ${ }^{45,52,54-57}$

Jet nebulizers use compressed air or oxygen from a wall system or the ventilator to generate an aerosol. Advantages of jet nebulizers include their low cost and their ability to synchronize with each breath. Disadvantages include variability in the amount of the drug delivered because the efficiency of the nebulizer depends on its position along the inspiratory limb relative to the endotracheal tube. It also causes the additional delivery of $6-8 \mathrm{~L}$ of gas into the ventilator circuit, thereby affecting the tidal volume the patient receives. ${ }^{54}$ Other disadvantages include longer duration of treatment, particle size variability, high residual volume, ${ }^{45,52}$ bulkiness of the machine, and the need for a power source. ${ }^{57}$ 


\section{Aerosolized Antibiotics in Mechanically Ventilated Subjects}

Table 3. Comparison of 3 Nebulizer Types

\begin{tabular}{|c|c|c|c|}
\hline & Power Source & Advantages & Disadvantages \\
\hline Jet nebulizer & $\begin{array}{l}\text { Compressed } \\
\text { gas/electrical }\end{array}$ & $\begin{array}{l}\text { Low cost } \\
\text { Capability of synchronizing with breath }\end{array}$ & $\begin{array}{l}\text { Long treatment time } \\
\text { Limited portability } \\
\text { Variable particle sizes } \\
\text { Low output rate } \\
\text { Lowest-efficiency nebulizer } \\
\text { High degree of performance variability } \\
\text { High residual drug volume }(0.8-2 \mathrm{~mL}) \\
\text { Possible risk for denaturing medication due } \\
\text { to shear stress }\end{array}$ \\
\hline Ultrasonic nebulizer & Electrical/batteries & $\begin{array}{l}\text { High efficiency } \\
\text { Intermediate treatment time } \\
\text { Intermediate degree of performance } \\
\quad \text { variability } \\
\text { Low residual volume }(0.4-1.2 \mathrm{~mL})\end{array}$ & $\begin{array}{l}\text { Limited portability } \\
\text { High cost } \\
\text { Hygiene concern due to ability for multiple } \\
\text { patient use } \\
\text { Solution temperature increases with use, } \\
\text { leading to high likelihood of denaturing } \\
\text { and inactivation of medication. }\end{array}$ \\
\hline Vibrating mesh nebulizer & Electrical/batteries & $\begin{array}{l}\text { Portable } \\
\text { Highest efficiency } \\
\text { Short treatment time } \\
\text { Lowest residual volume }(0.2 \mathrm{~mL}) \\
\text { Small particle size } \\
\text { Minimal change in solution temperature, } \\
\text { less likely to denature and inactivate } \\
\text { antibiotic }\end{array}$ & $\begin{array}{l}\text { High cost } \\
\text { Does not allow for breath synchronization* } \\
\text { Difficulty with cleaning } \\
\text { Potential for pore clogging }\end{array}$ \\
\hline
\end{tabular}

* A breath-synchronized vibrating mesh nebulizer is under investigation. ${ }^{53}$

Table modified from References 45,52,54-57.

Ultrasonic nebulizers create high-frequency vibrations through a piezoelectric crystal to generate aerosols. The particle size generated depends on the frequency of vibration: the higher the frequency, the smaller the droplet size. Ultrasonic nebulizers are considered more efficient than jet nebulizers in delivering drug to the lungs due to their ease of use and lower drug residual volume. However, several disadvantages of ultrasonic nebulizers include their higher cost, bulkiness, and the potential to denature and inactivate the medication by heating the solution after the nebulizer has been in operation for $10-15 \min .52,54$

With vibrating mesh nebulizers, the nebulizer and reservoir unit generate aerosols by vibration of a plate, and liquid droplets $1-5 \mu \mathrm{m}$ in size are pumped through uniform holes. These nebulizers provide efficient drug delivery, low residual volume, and ease of use, including portability and the option to use either a battery pack or power source. ${ }^{45}$ However, vibrating mesh nebulizers are more costly and lack the ability to synchronize aerosol generation with each breath. ${ }^{52} \mathrm{~A}$ breath-synchronized vibrating mesh nebulizer, the Pulmonary Drug Delivery System (PDDS; Nektar Therapeutics, San Carlos, CA), designed to deliver amikacin as an adjunct to systemic antibiotics for treatment of lower respiratory tract infections is under investigation. With the PDDS, inhaled amikacin can be used in patients who are receiving mechanical ventilation, those breathing spontaneously after extubation, as well as those patients receiving noninvasive positive-pressure ventilation. ${ }^{55}$

Ventilator settings that can optimize drug delivery to the lung parenchyma include utilizing the volume-controlled mode with higher tidal volumes and longer inspiratory times. Ventilator settings such as humidity, inspiratory time, and flow, along with the placement of the nebulizer, influence antibiotic delivery to the lungs. ${ }^{45,52,54,58}$ Bench models demonstrate a decrease in drug delivery with heated or humidified circuits; however, potential complications may occur with delivering the medication in a dry circuit. Adding humidity to the system assists in promoting normal mucociliary clearance, reduces the possibility of bronchospasm, and prevents drying of airway mucosa, all of which are often associated with utilizing dry gas. The density of inhaled gas also needs to be considered. A less dense gas, such as heliox, reduces air-flow turbulence and improves deposition of a drug aerosol in the lungs. ${ }^{45,58}$

Finally, the selected antibiotics should possess certain properties to ensure efficacy and safety. ${ }^{46}$ The ideal antibiotic solution selected for treatment of VAP should possess certain characteristics to ensure its safety and optimal 


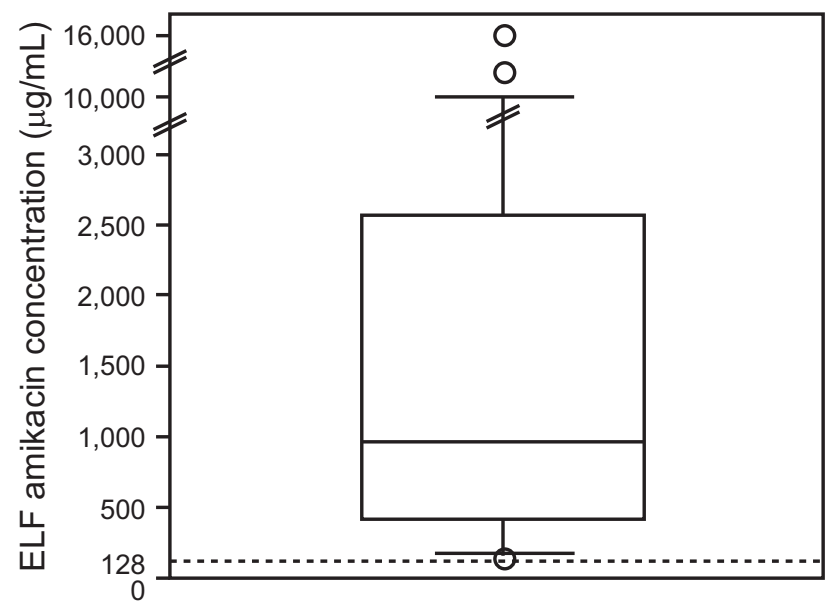

Fig. 1. Amikacin levels in epithelial lining fluid (ELF) at day 3. The dotted line corresponds to $128 \mu \mathrm{g} / \mathrm{mL}$, which is 10 times the critical $90 \%$ minimum inhibitory concentration for Pseudomonas aeruginosa. T-bars represent the 10th and 90th percentiles, and the horizontal line in the box is the median; the lower and upper limits of the box represent the 25th and 75th percentiles, respectively. Circles represent outliers. From Reference 12, with permission.

delivery. For example, IV drug formulations should not be employed because they may contain harmful preservatives and have greater potential to cause adverse side effects such as bronchospasm. ${ }^{47}$ Bassetti and co-workers ${ }^{59}$ described the ideal nebulized or inhaled antibiotic to be nonpyrogenic, sterile, free of preservatives, with a $\mathrm{pH}$ level of $4.0-8.0$, and adjusted tonicity and osmolarity of $150-$ $1,200 \mathrm{mOsm} / \mathrm{L}$.

\section{Pharmacokinetics}

The earliest method employed to deliver antibiotics to the lung parenchyma utilized intratracheal administration. Direct intratracheal instillation of antibiotics increased drug levels in bronchial secretions over that in plasma, and this technique was associated with higher bactericidal activity of the antibiotic in the lungs. ${ }^{48}$

Luyt et al $^{12}$ proposed that adding aerosolized amikacin to IV antibiotics for treatment of Gram-negative VAP led to much higher levels of amikacin in the lung tissues (eg, a median concentration of $976.1 \mu \mathrm{g} / \mathrm{mL}$ ) while maintaining safe serum levels below the threshold for development of nephrotoxicity (Fig. 1). In their study, 28 subjects received $400 \mathrm{mg}$ nebulized amikacin in addition to IV antibiotics. They reported high levels of amikacin in the epithelial lining fluid in areas that were affected by infection, and amikacin levels in epithelial lining fluid were 4-10 times higher than the 90\% minimum inhibitory concentration of pathogens usually implicated in VAP.
Among subjects who did not require mechanical ventilation, Cipolla and co-workers ${ }^{60}$ evaluated the efficacy of liposomal ciprofloxacin to treat pulmonary infections due to $P$. aeruginosa. Their study showed that the concentration of the medication in the sputum exceeded the minimum inhibitory concentration by $>50$-fold. The serum concentrations after inhalation were much lower than those found when the medication was administered orally (Fig. 2).

Niederman and colleagues ${ }^{13}$ administered inhaled amikacin with the PDDS breath-synchronized delivery system to 69 mechanically ventilated subjects with Gram-negative pneumonia. Subjects received either $400 \mathrm{mg}$ amikacin every $12 \mathrm{~h}$, amikacin $400 \mathrm{mg}$ every $24 \mathrm{~h}$, or placebo for 7-14 d. Tracheal aspirate samples were collected at various times during the study (Fig. 3); on days 1, 3, 14; $3 \mathrm{~d}$ after last dose; and 28-31 d after the first dose. The primary end point was an amikacin minimum inhibitory concentration of $256 \mu \mathrm{g} / \mathrm{mL}$, a level derived from a prior study assessing in vitro amikacin susceptibility for Gramnegative pathogens isolated from ICUs across North America. ${ }^{13}$

The pharmacokinetics of aerosolized colistin in 20 mechanically ventilated subjects with ventilator-associated tracheobronchitis were determined by measuring the drug levels in epithelial lining fluid after a single administration of $80 \mathrm{mg}$ aerosolized colistimethate sodium. ${ }^{14}$ The investigators measured colistin levels with bronchoalveolar lavage before initiation of study and at 1, 4, and $8 \mathrm{~h}$ after administration of colistimethate sodium (Fig. 4). Serum colistin levels were obtained before treatment as well as at various times during the day (ie, at $0.16,0.5,1,4$, and $8 \mathrm{~h}$ ) (Fig. 4). The levels of colistin in the epithelial lining fluid were highest within the first $4 \mathrm{~h}$ of drug administration, especially during the first hour, and were above the minimum inhibitory concentration level for all of the cultured pathogens, although still below the minimum inhibitory concentration threshold according to the European Committee on Antimicrobial Susceptibility Testing (EUCAST) standards for A. baumannii and K. pneumoniae. The serum levels of colistin were lower than the colistin levels in the epithelial lining fluid (Fig. 4). ${ }^{14}$

\section{Clinical Application of Aerosolized Antibiotics for Treatment of VAP}

\section{For Prevention}

The majority of efforts directed at the prevention of VAP aim to limit the ability of pathogens to reach the lower respiratory tract, such as oral care, sedation holidays, and other measures. ${ }^{15,61}$ Previous investigators utilized antibiotics, including those administered via nebulizers, to reduce bacterial colonization of the airways as a 


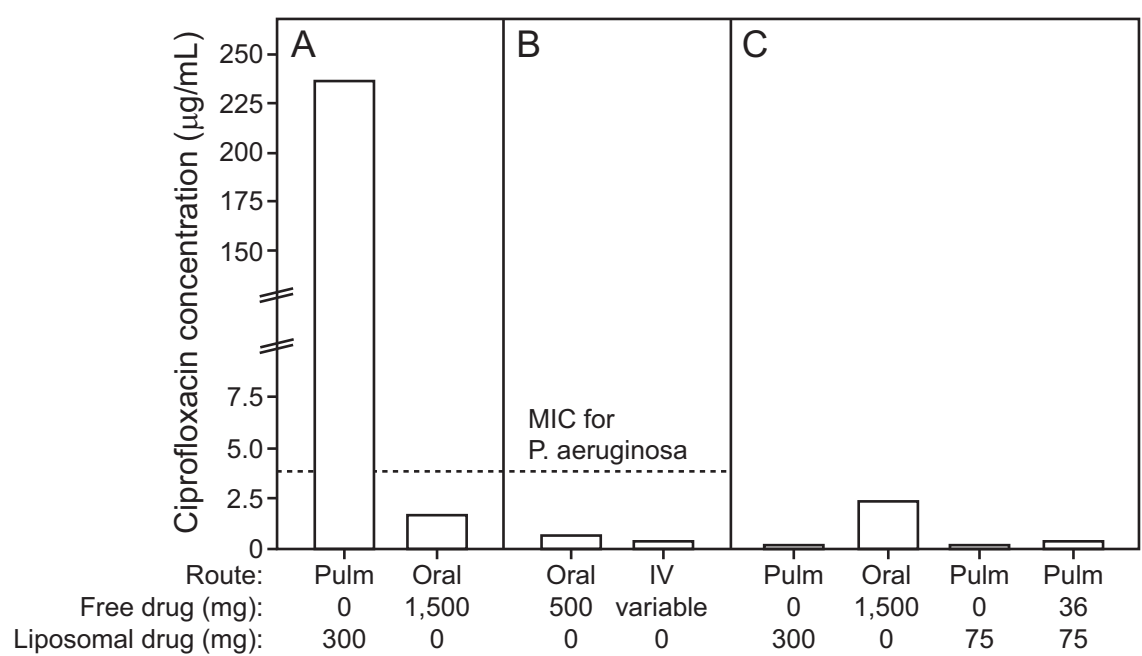

Fig. 2. The concentration of ciprofloxacin in lung sputum, bronchial secretions (mean concentration), and serum following inhaled (Pulm), oral, or intravenous (IV) administration. The oral and IV formulations contained unencapsulated (free) ciprofloxacin, while the inhaled formulations contained liposomal ciprofloxacin or combinations of free and liposomal ciprofloxacin. The oral dose, even at twice the maximum labeled dose of $750 \mathrm{mg}$, leads to a maximum drug concentration in the sputum lower than the MIC for $P$. aeruginosa in the biofilm of $4 \mu \mathrm{g} / \mathrm{mL}$, represented by the dotted line. In contrast, the maximum drug concentration in the sputum by inhalation exceeds the MIC by more than 50 -fold, and the mean concentration over the 24-h dosing period exceeds the MIC by 20 -fold. However, the peak serum drug concentration following inhalation is only a fraction (3-5\%) of that for oral dosing, thus reducing the potential for systemic side effects. $\mathrm{MIC}=$ minimum inhibitory concentration. From Reference 60, with permission.

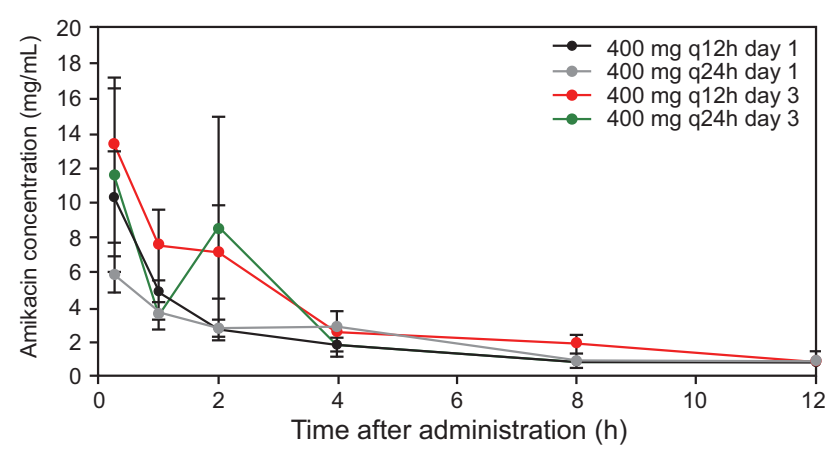

Fig. 3. Amikacin concentrations in tracheal aspirate after day 1 and day 3 in all treated subjects. Values are for all treated subjects with tracheal aspirate amikacin concentrations at the relevant time point. $\mathrm{q} 12 \mathrm{~h}=$ every $12 \mathrm{~h} ; \mathrm{q} 24 \mathrm{~h}=$ every $24 \mathrm{~h}$. From Reference 13, with permission.

means to prevent VAP. However, there are concerns about using antibiotics for this purpose because of the rising epidemic of infections with MDR organisms. ${ }^{61}$ Karvouniaris and co-workers ${ }^{16}$ investigated the prophylactic use of nebulized colistin for VAP in critical care units where VAP due to MDR Gram-negative bacilli were prevalent. Subjects $(N=168)$ received colistin versus saline $6.5-7 \mathrm{~h}$ after intubation. Although fewer subjects developed VAP in the intervention group compared to the control group ( $16.7 \%$ vs $29.8 \%$ ), the difference was not statistically significant. There was also no difference between the 2 groups regarding ICU or hospital mortality. The investigators noted that subjects who developed VAP despite receiving pro- phylactic nebulized colistin had a significantly lower ICU mortality compared with those receiving placebo. Moreover, there was no difference in the development of colistin-resistant bacteria between the intervention and control groups. ${ }^{16}$

Wood and colleagues ${ }^{17}$ investigated the efficacy of aerosolized ceftazidime to prevent pneumonia in mechanically ventilated trauma subjects. In their study, 40 subjects received either ceftazidime or placebo every $12 \mathrm{~h}$ for $7 \mathrm{~d}$. In those who received empiric ceftazidime, the incidence of VAP decreased by $73 \%$ at ICU day 14 , and there was a $54 \%$ reduction during the entire ICU stay. In addition, those subjects receiving empiric antibiotics received less systemic antibiotics compared with those receiving placebo. ${ }^{17}$ A meta-analysis by Povoa and co-workers ${ }^{15}$ included 1,158 subjects in 6 studies that investigated the role of antibiotics administered either intratracheally or via the nebulizer to prevent VAP. Their results indicated that the weighted pooled proportion (meta-proportion) from all of the reviewed studies for VAP was $32 \%(P=.02)$, and the pooled odds ratio (meta-odds ratio) for developing pneumonia was 0.53 compared to control. Inhaled or nebulized antibiotics provided the greatest protective effect, and in 2 studies the prophylactic use of antibiotics did not increase the development of VAP caused by MDR organisms.

Prophylactic aerosolized ceftazidime administration in 105 trauma subjects deemed at high risk for developing pneumonia was investigated in another study by 

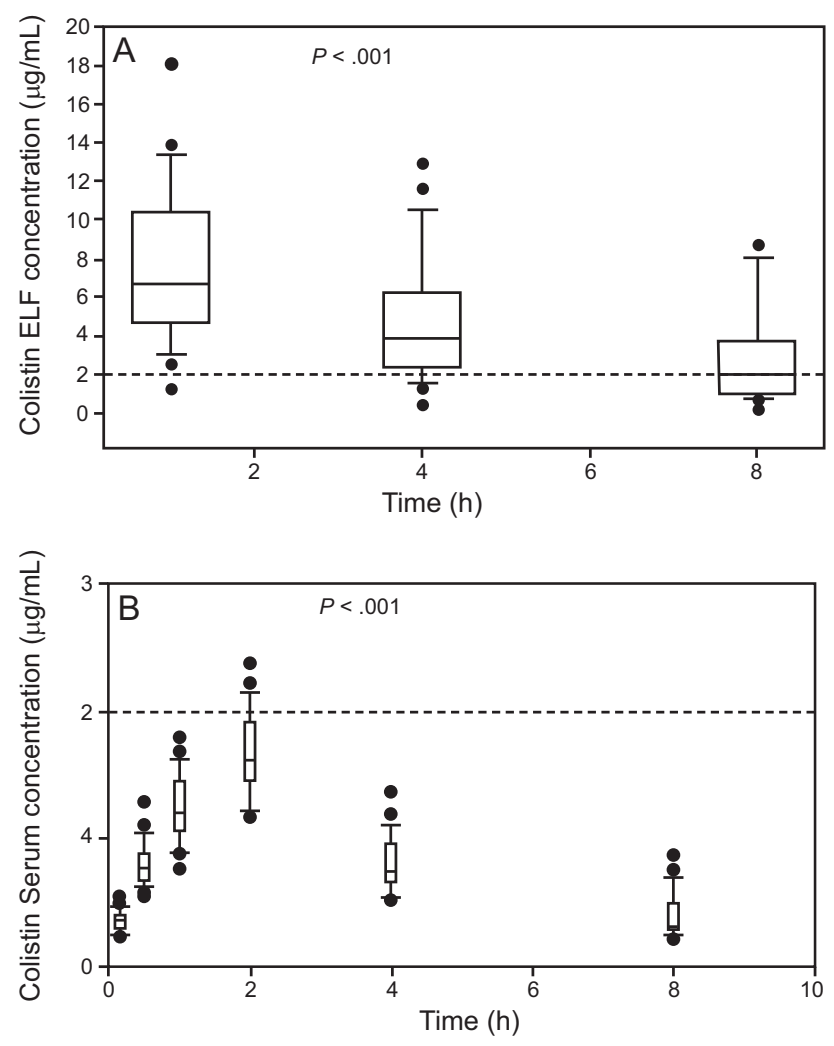

Fig. 4. Levels of colistin in ELF (A) at 1, 4, and $8 \mathrm{~h}$ after administration of $80 \mathrm{mg}$ nebulized colistemethate sodium. Serum colistin concentrations $(B)$ at $0.16,0.5,1,2,4$, and $8 \mathrm{~h}$ after administration of $80 \mathrm{mg}$ nebulized colistemethate sodium. Median levels and interquartile ranges are shown. Dashed lines represent minimum inhibitory concentration (MIC) for A. baumannii, K. pneumoniae, according to EUCAST susceptibility. Adapted from Reference 14, with permission.

Claridge and colleagues. ${ }^{18}$ The investigators considered factors such as the mechanism of injury, presence of spinal cord injury, and the number of blood products received. The primary outcome measure was the diagnosis of VAP at 14 and $30 \mathrm{~d}$ after the admission date. Subjects received either nebulized ceftazidime or placebo every $12 \mathrm{~h}$ for $7 \mathrm{~d}$ or until the subject was either extubated or removed from the ventilator. The investigators were unable to demonstrate a significant difference in either group in diagnosis of VAP at 14 and $30 \mathrm{~d} .{ }^{18}$ Similar to previous studies, there was no significant difference in the development of infections due to MDR bacteria in either group. ${ }^{18}$

The use of aerosolized antibiotics for the prevention of VAP appears to be an attractive option, but there is no conclusive evidence that this approach is successful, and there is a risk of introducing antibiotic-resistant organisms when antibiotics are used widely in critically ill patients in the ICU. Thus, aerosolized antibiotics are not recommended for prevention of VAP.

\section{As Monotherapy}

The 2016 Infectious Disease Society of America (IDSA) and American Thoracic Society (ATS) Guidelines for treatment of pneumonia did not have clear recommendations for using inhaled antibiotics as the sole therapy for pneumonia in mechanically ventilated patients. ${ }^{7}$ However, several investigations and meta-analyses reported the noninferiority or benefits of treating pulmonary infections with inhaled agents. A randomized phase- 2 trial by $\mathrm{Lu}$ et al ${ }^{19}$ evaluated the efficacy and safety of administering combined amikacin and ceftazidime to treat VAP due to $P$. aeruginosa in predominantly trauma or post-surgical subjects. Subjects $(N=40)$ were assigned to receive the combined regimen in either the aerosolized or IV formulation. In the aerosolized group, subjects received 8 treatments of ceftazidime for $8 \mathrm{~d}$ along with once-daily amikacin for $3 \mathrm{~d}$. In the IV group, subjects were administered a bolus of ceftazidime followed by continuous infusion for $8 \mathrm{~d}$ as well as a daily amikacin bolus for $3 \mathrm{~d}$. Three subjects infected with intermediate strains received nebulized ceftazidime and amikacin in the aerosolized group, but for the IV group, IV amikacin was replaced by ciprofloxacin. The cure rate at the end of treatment was achieved in $70 \%$ of subjects in the aerosol group versus $55 \%$ in the IV group $(P=.33)$. Treatment failure, defined as the persistence of VAP, was observed in 3 subjects in the aerosol group versus 6 subjects in the IV group. ${ }^{19}$

An earlier study by Berlana and co-workers ${ }^{62}$ evaluated the use of colistin in various formulations to treat MDR Gram-negative infections. These investigators reported that inhaled colistin was effective as either monotherapy or as adjunctive therapy for infections due to Acinetobacter species. Three subjects in the aerosolized group showed persistence of the pathogen, but the organism remained susceptible to colistin by susceptibility testing. ${ }^{62}$

A meta-analysis by Tulli and colleagues ${ }^{20}$ examined the non-inferiority of colistin compared to standard of care for VAP. Data from 8 controlled studies included 5 studies using IV colistin and 3 studies investigating inhaled colistin. Their analysis showed that aerosolized colistin was non-inferior to standard of care antibiotics currently used for VAP. ${ }^{20}$

Current guidelines do not recommend aerosolized antibiotics as monotherapy for patients with VAP, but a few investigators have reported that such an approach may be successful in select patients. However, selective use of aerosolized antibiotics is unlikely to gain approval by regulatory bodies, and large-scale randomized studies are needed to determine if the benefit of monotherapy with aerosolized antibiotics, especially inhaled colistin, can be consistently demonstrated in patients with VAP. 


\section{As Adjunct Therapy With Systemic Antibiotics}

A number of investigators have reported the use of nebulized antibiotics as an adjunct to systemic antibiotics for treatment of VAP, especially due to MDR Gram-negative bacilli (Table 4). The 2016 IDSA/ATS guidelines gave a weak recommendation for adjunctive treatment with the combination of IV and inhaled antibiotics for VAP due to Gram-negative infections that are susceptible only to aminoglycosides or polymyxins. ${ }^{7}$

A retrospective cohort study by Arnold and co-workers $^{26}$ examined the role of adding inhaled antimicrobials along with systemic antibiotics for treating VAP due to $P$. aeruginosa or A. baumannii confirmed with bronchoalveolar lavage. Ninety-three subjects received either inhaled colistin $150 \mathrm{mg}$ or tobramycin $300 \mathrm{mg}$ twice a day or placebo, depending on sensitivity results, in addition to systemic antibiotics. Their study did not demonstrate any significant differences in mechanical ventilation duration, length of hospital stay, and length of ICU stay with aerosolized antibiotics. However, subjects who received aerosolized antibiotics had lower 30-d mortality rates compared to those in the placebo group (0\% vs $17.6 \%){ }^{26}$

A multi-center retrospective study by Doshi and colleagues evaluated the efficacy of adding aerosolized colistin for the treatment of MDR Gram-negative pneumonia in ventilated ICU subjects. ${ }^{34}$ The most commonly isolated pathogens were A. baumannii and P. aeruginosa. The 95 enrolled subjects were assigned to receive either IV colistin alone or combined IV and aerosolized colistin, with the incidence of clinical cure as the primary end point. The group receiving combined therapy had a higher clinical cure rate compared with those who received IV colistin alone $(54.5 \%$ vs $39.2 \% ; P=.14)$. In addition, a subgroup of subjects diagnosed with bronchoalveolar lavage also had a higher clinical cure rate of $57.1 \%$ with combination therapy as opposed to $31.3 \%$ with IV administration alone, a statistically significant difference $(P=.033)$. Another observation was that subjects who received IV colistin were more likely to receive more IV antibiotics. ${ }^{34}$ Similarly, 86 subjects in a matched control study were assigned to receive either combined IV and aerosolized colistin (ASIV) versus IV colistin alone for Gram-negative pathogens causing VAP. Subjects who received the combined formulation had a slightly higher clinical cure rate (54\%) than those who received IV colistin alone $(32.5 \%){ }^{23}$ There was also a trend toward a lower ICU mortality rate in the AS-IV group compared to the IV group (23\% vs $42 \%$ ); however, there was no significant difference in all-cause mortality or VAP-related mortality in either group. ${ }^{23}$

The IASIS trial was the largest randomized study published to date that attempted to evaluate the safety and efficacy of adjunctive therapy with inhaled antibiotics using a combination of inhaled antibiotics with IV antibiot- ics that provided broad spectrum coverage against Gramnegative organisms. Kollef et ${ }^{31}$ al enrolled 143 subjects with VAP due to Gram-negative organisms. In this phase-2, placebo-controlled, international, multi-center, randomized study, subjects received either amikacin fosfomycin inhalation system or placebo daily for up to $10 \mathrm{~d}$. Each subject concurrently received at least $7 \mathrm{~d}$ of either IV meropenem or imipenem. There was no difference between the 2 groups in composite end points of mortality and time to clinical cure, or mortality and ventilator free days. However, the group treated with the amikacin fosfomycin inhalation system had fewer ventilator-free days compared to the placebo group $(P=.06)$. The group treated with the amikacin fosfomycin inhalation system had fewer positive tracheal aspirates on day 3 and 7 compared to the placebo group. The rate of adverse effects was similar in both groups. ${ }^{31}$

A randomized, placebo-controlled, phase-2, multi-center study by Niederman and colleagues ${ }^{13,35}$ evaluated the use of the investigational PDDS device to administer inhaled amikacin for treatment of Gram-negative pneumonia. Their results showed that subjects who received inhaled amikacin had lower IV antibiotic use along with lower failure rates. ${ }^{13}$

A phase-3, prospective, international, multi-center, randomized, placebo-controlled study of aerosolized amikacin in combination with IV antibiotics in intubated patients with Gram-negative VAP enrolled $>700$ subjects. ${ }^{33}$ Mechanically ventilated patients with pneumonia, about half of whom had VAP, were included. The PDDS, which is a breath-synchronized vibrating mesh nebulizer, administered either aerosolized amikacin $(400 \mathrm{mg}$ in normal saline) or normal saline every $12 \mathrm{~h}$, concurrent with IV antibiotics for $10 \mathrm{~d} .{ }^{33}$ For the primary end point of the study, the investigators analyzed survival at days $28-32$ in all subjects who received the study drug, had infection with a Gram-negative pathogen, and an APACHE II score of at least 10 at the time of diagnosis. They analyzed secondary efficacy end points in the following hierarchical order: pneumonia-related mortality, early clinical response, the number of days on mechanical ventilation, and the number of ICU days. Early clinical response was a composite end point based on Clinical Pulmonary Infection Score on days 3, 5, and 10 versus baseline, on the presence of empyema or lung abscess, and on all-cause mortality up to the end of treatment. The study design allowed for the evaluation of inhaled antibiotics as first-line adjunctive therapy, for a suspected pulmonary infection with a Gramnegative pathogen, compared to utilizing this agent for rescue therapy after cultures were positive. At the time of this review, the preliminary results indicate that the study did not meet its primary end point.

Previous studies, especially with amikacin or colistin for treatment of VAP due to Gram-negative bacilli, have reported potential clinical benefits with using these agents as 


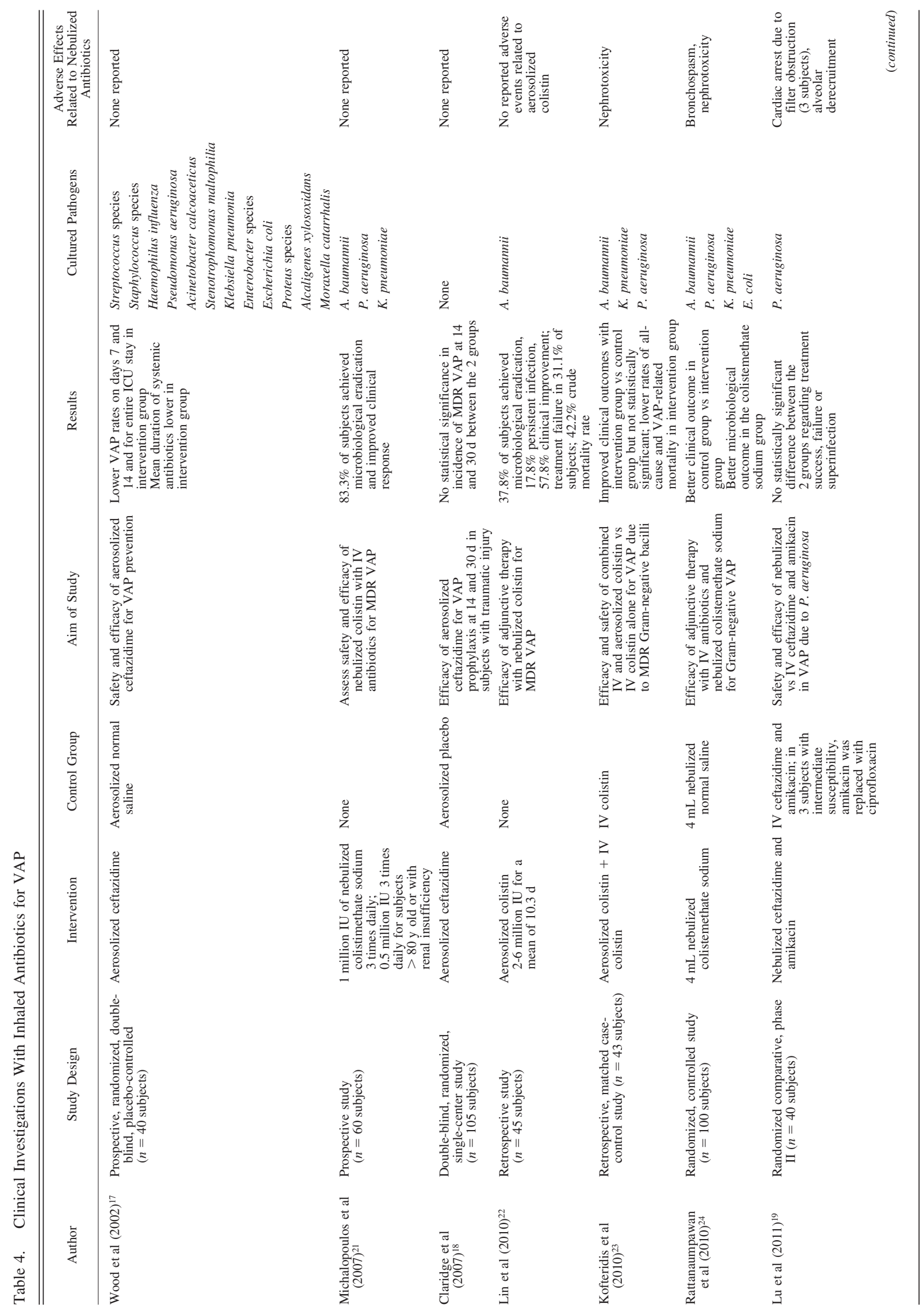




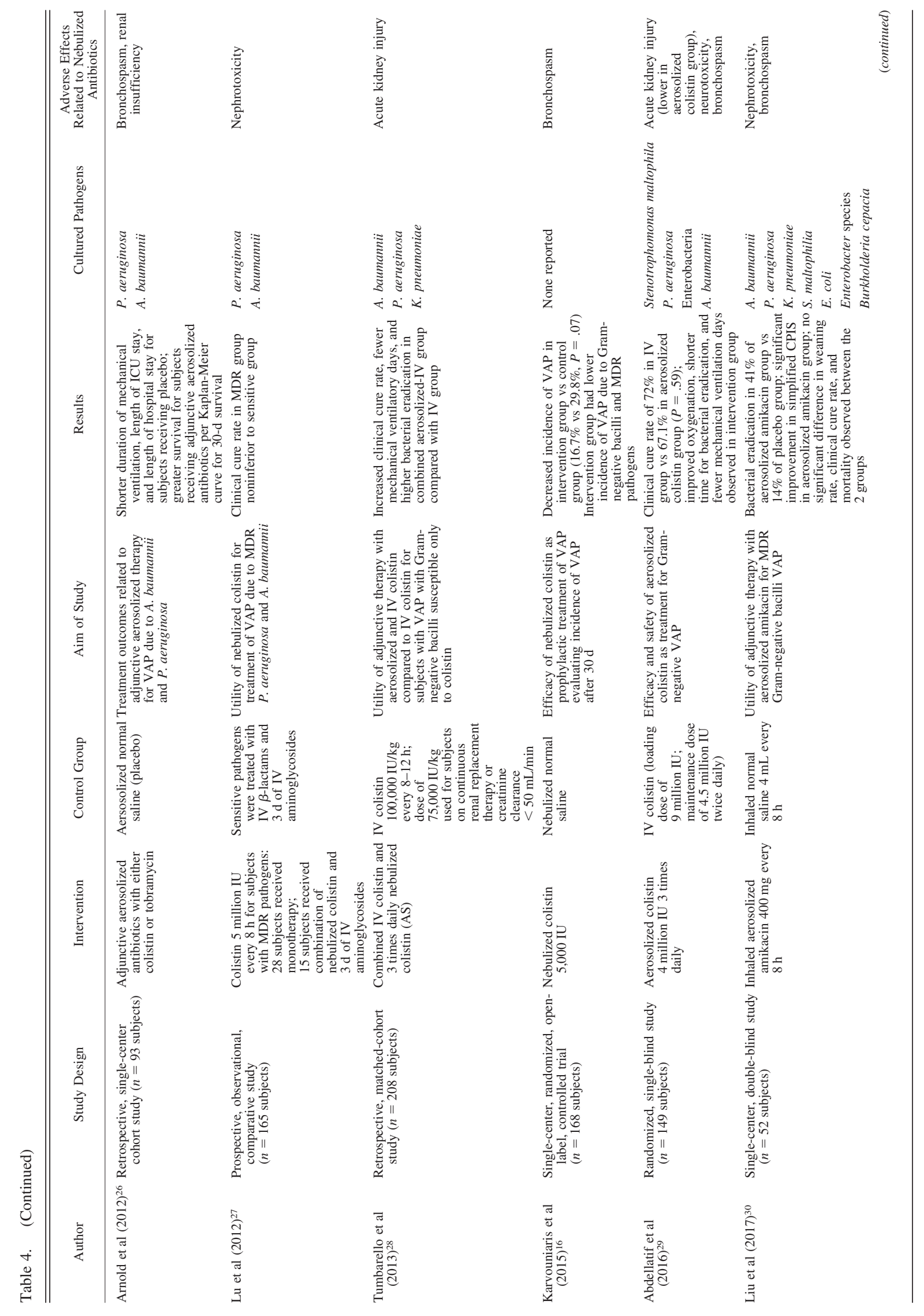




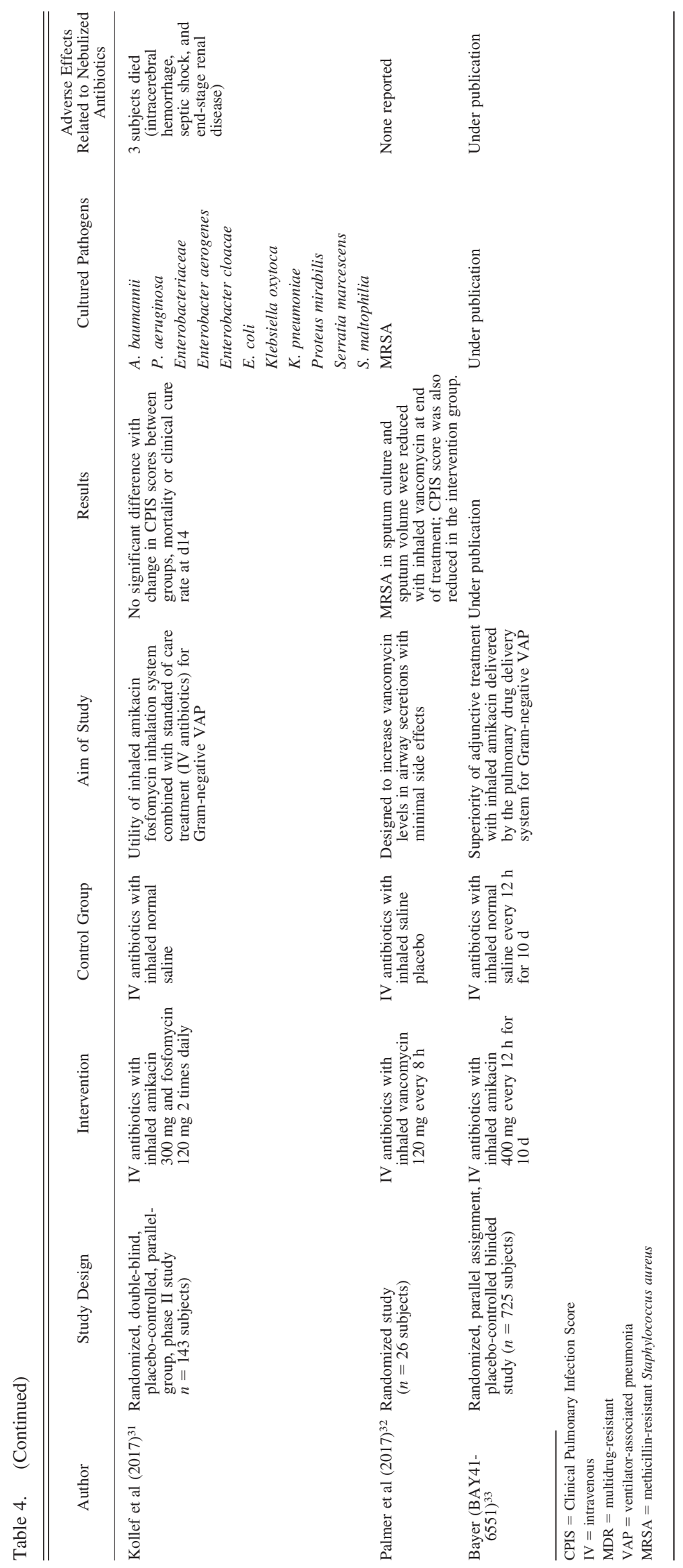


adjuncts to systemic antibiotics. However, recently concluded large, randomized, controlled trials have failed to report a benefit of adding aerosolized antibiotics to systemic therapy for VAP. ${ }^{31,33}$ Therefore, no new evidence has been provided to change the IDSA/ATS guidelines that adjunct therapy with aerosolized and IV antibiotics may be considered for pathogens that are susceptible only to inhaled aminoglycosides or polymyxins such as colistin. ${ }^{7}$

\section{For Treatment of Extensively Drug-Resistant or Pan Drug-Resistant Infections}

VAP due to $P$. aeruginosa or $A$. baumannii is associated with serious complications such as increased recurrence and potential development of antibiotic-resistant strains. There is growing concern for ways to treat infections due to these bacteria, especially when they develop into MDR or-even worse-extensively drug-resistant or pan drug-resistant pathogens. In view of the increasing prevalence of MDR pathogens, there is renewed interest in using colistin to treat and eradicate these dangerous pathogens. Although IV colistin has traditionally been employed for treating these infections, there are questions regarding its efficacy in treating pulmonary infections because IV colistin is associated with poor lung tissue penetration. Several investigators have investigated the role of inhaled colistin as an adjunct to systemic therapy or as monotherapy for treating these serious infections.

Lu and colleagues ${ }^{27}$ investigated the efficacy of treating VAP due to MDR Pseudomonas and Acinetobacter pneumonia in a single-center, prospective, observational study. Enrolled subjects $(n=165)$ were initially divided into a sensitive or MDR strain group. The group with the sensitive strain was treated with IV $\beta$-lactam antibiotic and $3 \mathrm{~d}$ of IV aminoglycosides. Those in the MDR strain group, comprising 43 subjects, were further divided into 2 subgroups. One subgroup was treated with 5 million IU of aerosolized colistin every $8 \mathrm{~h}$ for 7-19 d or until extubated via a vibrating mesh nebulizer in conjunction with $3 \mathrm{~d}$ of IV aminoglycosides; the other subgroup received monotherapy with aerosolized colistin. The study did not show a significant difference in clinical cure rate between the group treated with nebulized colistin and the group treated with IV $\beta$-lactam (67\% vs 66\%). ${ }^{27}$ There was an observed radiologic benefit in 7 subjects who were successfully treated with aerosolized colistin, showing increased gas and reduced tissue volume in areas with confluent pneumonia. There was no observed increased risk of developing resistance to colistin in the aerosolized group. ${ }^{27}$

Sharing similar characteristics to the study performed by Lu et al, ${ }^{27}$ Tumbarello and colleagues ${ }^{28}$ investigated the treatment of pneumonia due to A. baumannii, $P$. aerugi$n o s a$, and $K$. pneumoniae with nebulized and IV colistin (AS-IV) compared to IV colistin monotherapy in a retro- spective, matched-cohort study. In this study, clinical cure rates were higher in the AS-IV colistin group than in the IV colistin group $(69.2 \%$ vs $54.8 \% ; P=.03)$. Another notable and significant finding was that subjects in the AS-IV group had a shorter duration of post-VAP mechanical ventilation at $8 \mathrm{~d}$ compared to $12 \mathrm{~d}$ for those who received IV colistin alone $(P=.001){ }^{28}$

A single-center, double blind, randomized study by Liu and co-workers ${ }^{30}$ examined the use of aerosolized amikacin as an adjunct treatment for pneumonia caused by MDR Gram-negative bacilli in mechanically ventilated subjects $(N=52)$ randomized into either an aerosolized amikacin group or a placebo group. The aerosolized amikacin group received $400 \mathrm{mg}$ amikacin for $20 \mathrm{~min}$ every $8 \mathrm{~h}$; the placebo group received normal saline with the same scheduled dosing for a duration of $7 \mathrm{~d}$. The primary end points were eradication of the infectious agent and the emergence of resistance to amikacin. Bacterial isolates were eradicated in $41 \%$ of subjects in the aerosolized amikacin group as opposed to $14 \%$ of subjects in the placebo group $(P=$ .02). Likewise, $41 \%$ of subjects receiving aerosolized amikacin showed bacterial eradication versus $16 \%$ in the placebo group $(P=.049)$. Emergence of new resistance to amikacin was not observed upon follow-up after $28 \mathrm{~d} .{ }^{30}$

Abdellatif et $\mathrm{al}^{29}$ evaluated the safety and advantages of inhaled colistin for treating VAP due to MDR Gram-negative pathogens. The 149 subjects enrolled in the study received $1 \mathrm{~g}$ IV meropenem 3 times daily, and they were divided into an intervention or a control group, with treatment lasting for $14 \mathrm{~d}$. The intervention group received 4 million IU aerosolized colistin for 30 min 3 times daily. The control group received IV colistin with loading dose of 9 million IU followed by a maintenance dose of 4.5 million IU twice daily. Subjects in the control group achieved a higher clinical cure rate of $72 \%$ compared to $67.1 \%$ in the intervention group, a statistically insignificant difference $(P=.59)$. The efficacy of aerosolized colistin was not inferior to IV colistin, but the risk of nephrotoxicity was lower with aerosolized colistin. Subjects in the aerosolized colistin group were liberated from the mechanical ventilator at $13 \mathrm{~d}$ versus $18 \mathrm{~d}$ for subjects in the IV colistin group. ${ }^{29}$ Additional advantages observed in those receiving aerosolized colistin were improved oxygenation and earlier eradication of bacteria.

Emergence of infections due to MDR and extensively drug-resistant pathogens is increasing in many ICUs throughout the world. These investigations offer some prospects for utilizing aerosolized antibiotics as a modality for treatment of patients infected with MDR or extensively drug-resistant pathogens, especially with inhaled colistin. The use of aerosolized antibiotics could improve clinical cure rates and reduce the duration of mechanical ventilation in such patients. 


\section{Aerosolized Antibiotics in Mechanically Ventilated Subjects}

\section{Limitations and Barriers to Use of Aerosolized Antibiotics}

The use of inhaled antibiotics is associated with adverse effects, which could be procedure-related or caused by local effects. A major complication is occlusion of the flow meter or the expiratory filter, which could have very serious consequences, including cardiac arrest. ${ }^{52,63,64}$ It is therefore necessary to check the peak airway pressure during antibiotic administration and exchange the expiratory filter after each treatment session. ${ }^{52}$

Some adverse effects are due to direct exposure of the lung tissues to the antibiotic aerosol. These local side effects include cough, dysphonia, throat irritation, bronchoconstriction, bronchospasm, and even hypoxemia. ${ }^{49,63,65}$ The occurrence of bronchospasm could be mitigated by administration of an aerosolized $\beta$-agonist. ${ }^{49,52}$ However, if this strategy is unsuccessful, aerosolized antibiotics may have to be discontinued.

The precise role of aerosolized antibiotics in mechanically ventilated patients has not been clearly elucidated. Several studies have demonstrated that aerosolized antibiotics produce higher concentrations in sputum, but the ability of the antibiotics to be delivered and absorbed in areas of dense consolidation in the lungs is a matter of debate. There are concerns that mucus plugs and consolidation may hinder or block the pathway between the trachea and lung tissues that harbor the infection. ${ }^{56}$

Several factors influence the variable concentration of antibiotics in the respiratory tract, including patient-related factors, drug characteristics, and the bacteria themselves. As described by Mukker and colleagues, ${ }^{66}$ patient-related factors include but are not limited to age, severity of disease, lung pathophysiology, and breathing pattern, all of which can affect particle deposition in the lungs. Drugrelated factors that can affect treatment include the medication's diffusion capability, in that those with slow absorption may allow for increased systemic absorption as well. As mentioned previously, the particle size affects where and how much drug deposits in the lungs. Larger particles deposit in the upper respiratory tract and centrally, whereas smaller particles (ie, $<1 \mu \mathrm{m}$ in size) are more likely to be exhaled. ${ }^{66}$ The bacteria themselves also affect the efficacy of antibiotics. For instance, bacteria such as $P$. aeruginosa may form a biofilm, which serves as a barrier that allows them to evade immune cells and antibiotic penetration. ${ }^{51}$

The development of resistance with inhaled antibiotics remains a matter of concern. The minimum inhibitory concentration is the amount of drug needed to prevent growth of the inoculum. In contrast, the mutant prevention concentration is the concentration of the antibiotic required to prevent the growth of mutant organisms. Concentrations between these 2 levels comprise the "mutant selection win- dow," which enables resistance to develop. Results from the IASIS trial with the inhaled amikacin fosfomycin inhalation system ${ }^{31}$ and randomized, controlled trials with inhaled ciprofloxacin in subjects with stable non-cystic fibrosis bronchiectasis found no statistically significant difference in the emergence of bacterial resistance between subjects who received inhaled antibiotics compared to the subjects who received standard-of-care therapy. ${ }^{51}$ Results from the INHALE trial $^{33}$ demonstrated that $7 \%$ of subjects treated with inhaled amikacin developed resistance during the treatment period.

Studies investigating the emergence of resistant bacteria have been inconsistent. Earlier investigative studies could not demonstrate a significant increase in the development of resistant pathogens after receiving treatment with inhaled antibiotics. A meta-analysis by Ioannidou et $\mathrm{al}^{67}$ found that $6.5 \%$ (3/46) of subjects developed resistant pathogens. Later, a double-blind, randomized, placebocontrolled study by Palmer and Smaldone ${ }^{68}$ enrolled a total of 47 subjects who were divided into an intervention group receiving aerosolized antibiotics and a control group that received placebo. Of the subjects who received the aerosolized antibiotics, $13 \%$ developed new resistance with the treatment compared to $55 \%$ of subjects in the placebo group. ${ }^{68}$ The intervention group also did not develop resistance to the aerosolized antibiotics administered. Thus, the risk for emergence of resistant pathogens with aerosolized antibiotics appears to be low and, based on current evidence, does not appear to be a limiting factor for using this treatment modality in patients with VAP. However, longer-term studies are needed to address the concern for emerging resistance with the use of aerosolized antibiotics.

In an international survey reported by Ehrman and coworkers, ${ }^{69}$ in which physicians who worked in ICUs were surveyed regarding their knowledge and practices in utilizing nebulized medications, $99 \%$ of physicians reported employing nebulized medications with mechanically ventilated patients. However, despite the high percentage of physicians who reported using this modality within their practice, only $\sim 30 \%$ used nebulized antibiotics. The majority of physicians (77\%) did not change ventilator settings during nebulizer treatments. In addition, about half of the respondents were not aware of the optimal size for droplets to ensure efficacious delivery of aerosolized medications, and a third of respondents did not exchange protective filters after delivery of nebulized antibiotics. ${ }^{69,70}$ Unfortunately, to date there are no well-defined dosing regimens to optimize the use of aerosolized antibiotics in mechanically ventilated patients with pneumonia. ${ }^{57}$ For optimal use of aerosolized antibiotics in the ICU, we must address the knowledge gap among physicians about nebulizer delivery techniques and define appropriate antibiotic dosing regimens. 


\section{Aerosolized Antibiotics in Mechanically Ventilated Subjects}

\section{The Future for Aerosolized Antibiotics}

Currently, no strong recommendations advocate the use aerosolized antibiotics to treat pneumonia. The IDSA/ATS guidelines gave a weak recommendation for using aerosolized antibiotics only in situations in which the infectious pathogen is susceptible to polymyxin or aminoglycosides. ${ }^{7}$ In contrast, the European Respiratory Society does not recommend the use of inhaled antibiotics at all; instead, their recommendation is to avoid the use of nebulized antibiotics for the treatment of VAP. ${ }^{71,72}$ The conflicting recommendations stem from the weak quality of evidence regarding the efficacy of aerosolized antibiotics in published studies.

The final results of the largest study to evaluate the efficacy of nebulized antibiotics as adjuncts to systemic antibiotics (ie, the amikacin INHALE study) are still pending. Similar research studies are needed to evaluate the optimal dose and regimen for VAP treatment, especially with inhaled colistin. The cost associated with this mode of treatment also warrants consideration. Furthermore, most studies to date have involved treating Gram-negative pathogens; however, studies evaluating antibiotics for treatment of other MDR pathogens, such as methicillin-resistant $S$. aureus, are very limited and warrant further investigation. Smaller studies investigating the use of inhaled colistin in higher doses have shown a possible role for the use of adjunct therapy with systemic antibiotics in treating VAP due to MDR pathogens. These observations should encourage future large investigations to evaluate the role of inhaled colistin in VAP caused by MDR and extensively drug-resistant pathogens.

\section{Conclusions}

VAP is one of the most commonly encountered infections affecting patients in the ICU, and it is associated with many complications, such as prolonged ICU and hospital stays, higher medical costs, and increased mortality risk. The combination of increasing rates of resistant pathogens and lack of availability of new antibiotics to treat these infections has led to a growing interest in utilizing aerosolized antibiotics as a modality of treatment. The use of aerosolized antibiotics allows for less systemic toxicity while achieving higher drug concentrations in the lung parenchyma compared with commonly employed systemic antibiotics for the treatment of pneumonia. There are 4 proposed clinical settings for inhaled antibiotics, including prevention, monotherapy, adjunct therapy with IV antibiotics, and treatment of extensively drug-resistant and even pan drug-resistant pathogens. Previous investigations have not clearly established a role for aerosolized antibiotics, and 2 recent randomized and placebo-controlled studies have failed to demonstrate an improvement in clinical out- comes with the use of inhaled antibiotics as an adjunct to systemic antibiotic therapy. However, inhaled colistin in higher than conventionally employed doses has been successful in the treatment of pneumonia due to MDR or extensively drug-resistant organisms. In view of observed adverse effects with the use of aerosolized antibiotics, both local and systemic, the optimal dose and regimens of treatment are not clearly established. Further investigations are needed to clarify the precise role of aerosolized antibiotics in a variety of clinical settings among patients receiving mechanical ventilation in the ICU.

\section{REFERENCES}

1. Ferrer M, Torres A. Epidemiology of ICU-acquired pneumonia. Curr Opin Crit Care 2018;24(5):325-331.

2. Kalanuria AA, Zai W, Mirski M. Ventilator-associated pneumonia in the ICU. Critical Care 2014;18(2):208.

3. Abu-Salah T, Dhand R. Inhaled antibiotic therapy for ventilatorassociated tracheobronchitis and ventilator-associated pneumonia: an update. Adv Ther 2011;28(9):728-747.

4. Craven DE, Hudcova J, Rashid J. Antibiotic therapy for ventilatorassociated tracheobronchitis: a standard of care to reduce pneumonia, morbidity and costs? Curr Opin Pulm Med 2015;21(3):250-259.

5. Martin-Loeches I, Coakley JD, Nseir S. Should we treat ventilatorassociated tracheobronchitis with antibiotics? Semin Respir Crit Care Med 2017;38:264-270.

6. Rello J, Ollendorf DA, Oster G, Vera-Llonch M, Bellm L, Redman R, Kollef MH; VAP Outcomes Scientific Advisory Group. Epidemiology and outcomes of ventilator-associated pneumonia in a large US database. Chest 2002;122(6):2115-2121.

7. Kalil AC, Metersky ML, Klompas M, Muscedere J, Sweeney DA, Palmer LB, et al. Management of adults with hospital-acquired and ventilator-associated pneumonia: 2016 Clinical Practice Guidelines by the Infectious Diseases Society of America and the American Thoracic Society. Clin Infect Dis 2016;63(5):e61-e111.

8. Rewa O, Muscedere J. Ventilator-associated pneumonia: update on etiology, prevention and management. Curr Infect Dis Rep 2011;13: 287-295.

9. Luyt CE, Hékimian G, Koulenti D, Chastre J. Microbial cause of ICU-acquired pneumonia: hospital-acquired pneumonia versus ventilator-associated pneumonia. Curr Opin Crit Care 2018;24(5):332338.

10. Palmer LB. Ventilator-associated infection: the role for inhaled antibiotics. Curr Opin Pulm Med 2015;21(3):239-242.

11. Wenisch C, Laferi H, Szell M, Smolle KH, Grisold A, Bertha G, Krause R. A holistic approach to MRSA eradication in citically ill patients with MRSA pneumonia. Infection 2006;34(3):148-154.

12. Luyt CE, Clavel M, Guntupalli K, Johannigman J, Kennedy JI, Wood $\mathrm{C}$, et al. Pharamacokinetics and lung delivery of PDDS-aerosolized amikacin (NKTR-061) in intubated and mechanically ventilated patients with nosocomial pneumonia. Crit Care 2009;13(6):R200.

13. Niederman MS, Chastre J, Corkery K, Fink JB, Luyt CE, Garcia MS. BAY41-6551 achieves bactericidal tracheal aspirate amikacin concentrations in mechanically ventilated patients with Gram-negative pneumonia. Intensive Care Med 2012;38(2):263-271.

14. Athanassa ZE, Markantonis SL, Fousferi MZ, Myrianthefs PM, Boutzouka EG, et al. Pharmacokinetics of inhaled colistemethate sodium (CMS) in mechanically ventilated critically ill patients. Intensive Care Med 2012;38:1779-1786.

15. Povoa FC, Cardinal-Fernandez P, Maia IS, Reboredo MM, Pinheiro $\mathrm{BV}$. Effect of antibiotics administered via the respiratory tract in the 


\section{Aerosolized Antibiotics in Mechanically Ventilated Subjects}

prevention of ventilator-associated pneumonia: a systematic review and meta-analysis. J Crit Care 2018;43:240-245.

16. Karvouniaris M, Makris D, Zygoulis P, Triantaris A, Xitsas S, Mantzarlis K, et al. Nebulised colistin for ventilator-associated pneumonia prevention. Eur Resp J 2015;46:1732-1739.

17. Wood GC, Boucher BA, Croce MA, Hanes SD, Herring VL, Fabian TC. Aerosolized ceftazidime for prevention of ventilator-associated pneumonia and drug effects on the proinflammatory response in critically ill trauma patients. Pharmacotherapy 2002;22(8):972-982.

18. Claridge JA, Edwards NM, Swanson J, Fabian TC, Weinberg JA, Wood C, Croce MA. Aerosolized ceftazidime prophylaxis against ventilator-associated pneumonia in high-risk trauma patients: results of a double-blind randomized study. Surgical Infections 2007;8(1): 83-90.

19. Lu Q, Yang J, Liu Z, Gutierrez C, Aymard G, Rouby JJ. Nebulized ceftazidime and amikacin in ventilator-associated pneumonia caused by Pseudomonas aeruginosa. Am J Respir Crit Care Med 2011;184: 106-115.

20. Tulli G, Messori A, Trippoli S, Marinai C. Non-inferiority of colistin compared with standard care for the treatment of ventilator-associated pneumonia. Int J Antimicrob Agents 2017;49(5):638-641.

21. Michalopoulos A, Fotakis D, Virtzili S, Vletsas C, Raftopoulou S, Mastora Z, Falagas ME. Aerosolized colistin as adjunctive treatment of ventilator-associated pneumonia due to multidrug-resistant Gramnegative bacteria: a prospective study. Respir Med 2008;102:407412.

22. Lin CC, Liu TC, Kuo CF, Liu CP, Lee CM. Aerosolized colistin for the treatment of multidrug-resistant Acinetobacter baumannii pneumonia: experience in a tertiary care hospital in Northern Taiwan. J Microbiol Immunol Infect 2010;43(4):323-331.

23. Kofteridis DP, Alexopoulou C, Valachis A, Maraki S, Dimopoulou D, Gerogopoulos D, Samonis G. Aerosolized plus intravenous colistin versus intravenous colistin alone for the treatment of ventilatorassociated pneumonia: a matched case-control study. Clin Infect Dis 2010;51(11):1238-1244.

24. Rattanaumpawan P, Lorsutthitham J, Ungprasert P, Angkasekwinai N, Thamlikitkul V. Randomized controlled trial of nebulized colistimethate sodium as adjunctive therapy of ventilator-associated pneumonia caused by Gram-negative bacteria. J Antimicrob Chemother 2010;65:2645-2649.

25. Lu Q, Girardi C, Zhang M, Bouhemad B, Louchahi K, Petitjean O, et al. Nebulized and intravenous colistin in experimental pneumonia caused by Pseudomonas aeruginosa. Intensive Care Med 2010;36: $1147-1155$.

26. Arnold HM, Sawyer AM, Kollef MH. Use of adjunctive aerosolized antimicrobial therapy in the treatment of Pseudomonas aeruginosa and Acinetobacter baumannii ventilator-associated pneumonia. Respir Care 2012;57(8):1226-1233.

27. Lu Q, Luo R, Bodin L, Yang J, Zahr N, Aubry A, et al. Efficacy of high-dose nebulized colistin in ventilator associated pneumonia caused by multidrug-resistant Pseudomonas aeruginosa and Acinetobacter baumannii. Anesthesiology 2012;117(6):1335-1347.

28. Tumbarello M, De Pascale G, Trecarichi EM, De Martino S, Bello $\mathrm{G}$, Maviglia R, et al. Effect of aerosolized colistin as adjunctive treatment on the outcomes of microbiologically documented ventilator-associated pneumonia caused by colistin-only susceptible gramnegative bacteria. Chest 2013;144(6):1768-1775.

29. Abdellatif S, Trifi A, Daly F, Mahjoub K, Nasri R, Lakhal B. Efficacy and toxicity of aerosolised colistin in ventilator-associated pneumonia: a prospective, randomised trial. Ann Intensive Care 2016; 6(1):26.

30. Liu C, Zhang YT, Peng ZY, Zhou Q, Hu B, Zhou H, Li JG. Aerosolized amikacin as adjunctive therapy of ventilator-associated pneumonia caused by multidrug-resistant gram-negative bacteria: a sin- gle-center randomized controlled trial. Chin Med J (Engl) 2017; 130(10):1196-1201.

31. Kollef MH, Ricard JD, Roux D, Francois B, Ischaki E, Rozgonyi Z, et al. A randomized trial of the amikacin fosfomycin inhalation system for the adjunctive therapy of gram-negative ventilator-associated pneumonia, IASIS Trial. Chest 2017;151(6):1239-1246.

32. Palmer LB, Smaldone GC. Eradication of MRSA ventilator-associated infection with inhaled vancomycin. Eur Respir J 2017;50(Suppl 61):OA4655

33. Bayer. Inhaled Amikacin Solution BAY41-6551 as adjunctive therapy in the treatment of gram-negative pneumonia (INHALE 1). Available at: https://clinicaltrials.gov/ct2/show/NCT01799993. NLM identifier: NCT01799993. Accessed February 6, 2019.

34. Doshi NM, Cook CH, Mount KL, Stawicki SP, Frazee EN, Personett HA, et al. Adjunctive aerosolized colistin for multi-drug resistant Gram-negative pneumonia in the critically ill: a retrospective study. BMC Anesthesiology 2013;13:45.

35. Niederman MS, Sanchez M, Corkery K, Guntupalli K, Luyt CE, Chastre J. NKTR-061 (inhaled amikacin) achieves high tracheal aspirate concentrations in intubated mechanically ventilated patients with gram-negative pneumonia: a pharmacokinetic study. Poster presented at the American Thoracic Society International Conference; May 2007; San Francisco, CA.

36. Vincent JL, Rello J, Marshall J, Silva E, Anzueto A, Martin CD, et al; EPIC II Group of Investigators. International study of the prevalence and outcomes of infection in intensive care units. JAMA 2009;302(21):2323-2329.

37. Metersky ML, Kalil AC. Management of ventilator-associated pneumonia guidelines. Clin Chest Med 2018;39(4):797-808.

38. Metersky ML, Wang Y, Klompas M, Eckenrode S, Bakullari A, Eldridge N. Trend in ventilator-associated pneumonia rates between 2005 and 2013. JAMA 2016;316(22):2427-2429.

39. Niederman MS, Craven DE; American Thoracic Society; Infectious Diseases Society of America. Guidelines for the management of adults with hospital-acquired, ventilator-associated, and healthcareassociated pneumonia. Am J Respir Crit Care Med 2005;171(4):388416.

40. Melsen WG, Rovers MM, Groenwold RH, Bergmans CJ, Camus C, Bauer TT, et al. Attributable mortality of ventilator-associated pneumonia: a meta-analysis of individual patient data from randomised prevention studies. Lancet Infect Dis 2013;13(8):665-671.

41. Keane S, Vallecoccia MS, Nseir S, Martin-Loeches I. How can we distinguish ventilator-associated tracheobronchitis from pneumonia? Clin Chest Med 2018;39(4):785-796.

42. Magill SS, Klompas M, Balk R, Burns SM, Deutschman CS, Dickerma $\mathrm{D}$, et al. Developing a new, national approach to surveillance for ventilator-associated events. Crit Care Med 2013;41(11):24672475.

43. Skrupky LP, McConnell K, Dallas J, Kollef MH. A comparison of ventilator-associated pneumonia rates as identified according to the National Healthcare Safety Network and American College of Chest Physicians criteria. Crit Care Med 2012;40(1):281-284.

44. Wood GC, Swanson JM. An update on aerosolized antibiotics for treating hospital-acquired and ventilator-associated pneumonia in adults. Ann Pharmacother 2017;51(12):1112-1121.

45. Dhand R, Guntur VP. How best to deliver aerosol medications to mechanically ventilated patients. Clin Chest Med 2008;29:277-296.

46. Restrepo MI, Keyt H, Reyes LF. Aerosolized antibiotics. Respir Care 2015;60(6):762-773.

47. Velkov T, Abdul Rahim N, Zhou QT, Chan HK, Li J. Inhaled antiinfective chemotherapy for respiratory tract infections: successes, challenges, and the road ahead. Adv Drug Deliv Rev 2015;85:65-82.

48. Palmer LB. Inhaled antibiotics for ventilator-associated infections. Infect Dis Clin North Am 2017;31(3):577-591. 


\section{Aerosolized Antibiotics in Mechanically Ventilated Subjects}

49. Quon BS, Goss CH, Ramsey BW. Inhaled antibiotics for lower airway infections. Ann Am Thorac Soc 2014;11(3):425-434.

50. Brodt AM, Stovold E, Zhang L. Inhaled antibiotics for stable noncystic fibrosis bronchiectasis: a systematic review. Eur Respir J 2014; 44(2):382-393.

51. Dhand R. The rationale and evidence for use of inhaled antibiotics to control Pseudomonas aeruginosa infection in non-cystic fibrosis bronchiectasis. J Aerosol Med Pulm Drug Deliv 2018;31:121-138.

52. Luyt CE, Hekiman G, Brechot N, Chastre J. Aerosol therapy for pneumonia in the intensive care unit. Clin Chest Med 2018;39(4): 823-836.

53. Palmer LB. Aerosolized antibiotics in the intensive care unit. Clin Chest Med 2011;32(3):559-574.

54. Dhand R. How should aerosols be delivered during invasive mechanical ventilation? Respir Care 2017;62(10):1343-1367.

55. Dhand R, Sohal H. Pulmonary drug delivery system for inhalation therapy in mechanically ventilated patients. Expert Rev Med Devices 2008;5(1):9-18

56. Zhang C, Berra L, Klompas M. Should aerosolized antibiotics be used to treat ventilator-associated pneumonia? Respir Care 2016; 61(6):737-748.

57. Weers J. Inhaled antimicrobial therapy - barriers to effective treatment. Adv Drug Deliv Rev 2015;85:24-43.

58. Dhand R. Aerosol delivery during mechanical ventilation: from basic techniques to new devices. J Aerosol Med Pulm Drug Deliv 2008; 21:45-60.

59. Bassetti M, Luyt CE, Nicolau DP, Pugin J. Characteristics of an ideal nebulized antibiotic for the treatment of pneumonia in the intubated patient. Ann Intensive Care 2016; 6(1):35.

60. Cipolla D, Blanchard J, Gonda I. Development of liposomal ciprofloxacin to treat lung infections. Pharmaceutics 2016;8:E6.

61. Bassi GL, Senussi T, Xiol EA. Prevention of ventilator-associated pneumonia. Curr Opin Infect Dis 2017;30:214-220.

62. Berlana D, Llop JM, Fort EF, Badia MB, Jodar R. Use of colistin in the treatment of multiple-drug-resistant gram-negative infections. Am J Health-Syst Pharm 2005;62:39-47.
63. Poulakou G, Matthaiou DK, Nicolau DP, Siakallis G, Dimopoulos G. Inhaled antimicrobials for ventilator-associated pneumonia: practical aspects. Drugs 2017;77(13):1399-1412.

64. Solé-Lleonart C, Rouby JJ, Chastre J, Poulakou G, Palmer LB, Blot $\mathrm{S}$, et al. Intratracheal administration of antimicrobial agents in mechanically ventilated adults: an international survey on delivery practices and safety. Respir Care 2016;61(8):1008-1014.

65. Rouby JJ, Bouhemad B, Monsel A, Brisson H, Arbelot C, Lu Q. Aerosolized antibiotics for ventilator-associated pneumonia: lessons from experimental studies. Anesthesiology 2012;117(6):1364-80.

66. Mukker JK, Shankar R, Singh P, Derendorf H. Pharmacokinetic and pharmacodynamic implications in inhalable antimicrobial therapy. Adv Drug Deliv Rev 2015;85:57-64.

67. Ioannidou E, Siempos II, Falagas ME. Administration of antimicrobials via the respiratory tract for the treatment of patients with nosocomial pneumonia: a meta-analysis. J Antimicrob Chemother 2007; 60(6):1216-1226

68. Palmer LB, Smaldone GC. Reduction of bacterial resistance with inhaled antibiotics in the intensive care unit. Am J Respir Crit Care Med 2014;189(10):1225-1233.

69. Ehrmann S, Roche-Campo F, Papa GF, Isabey D, Brochard L, ApiouShirlea G. Aerosol therapy during mechanical ventilation: an international survey. Intensive Care Med 2013;39:1048-1056.

70. Wenzler E, Fraidenburg DR, Scardina T, Danziger LH. Inhaled antibiotics for Gram-negative respiratory infections. Clin Microbiol Rev 2016;29(3):581-632

71. Rello J, Solé-Lleonart C, Rouby JJ, Chastre J, Blot S, Poulakou $\mathrm{G}$, et al. Use of nebulized antimicrobials for the treatment of respiratory infections in invasively mechanically ventilated adults: a position paper from the European Society of Clinical Microbiology and Infectious Diseases. Clin Microbiol Infect 2017;23(9): 629-639.

72. Torres A, Niederman MS, Chastre J, Ewig S, Fernandez-Vandellos $\mathrm{P}$, Hanberger $\mathrm{H}$, et al. International ERS/ESICM/ESCMID/ALAT guidelines for the management of hospital-acquired pneumonia and ventilator-associated pneumonia. Eur Respir J 2017;50(3):1700582. 